Long V. Adventures in psychiatry: narrating and enacting reform in post-war mental healthcare. Studies in the Literary Imagination 2016, 48(1), 109-125.

DOI link

https://doi.org/10.1353/sli.2015.0007

ePrints link

http://eprint.ncl.ac.uk/247114

Date deposited

$16 / 04 / 2018$

Copyright

(C) Georgia State University 


\section{Vicky Long}

\section{Adventures in Psychiatry: Narrating and Enacting Reform in Post-War}

\section{Mental Healthcare}

The development of psychiatry owed much to the establishment of pauper lunatic asylums throughout Britain in the second half of the nineteenth century. However, the low status of these institutions, combined with psychiatrists' failure to devise effective treatment methods, meant that psychiatry did not enjoy a prestigious reputation in the nineteenth and early twentieth centuries. The post-war era, however, is commonly viewed as a period of rapid change in British mental healthcare. Mental hospitals were brought within the provisions of the new National Health Service in 1948, and this development provided psychiatrists and other mental health care workers with an opportunity to raise the status of psychiatry by reframing the profession as just another branch of medicine. Yet there was little consensus as to how progress was to be achieved, for psychiatrists were developing seemingly antithetical therapeutic models, premised on divergent understandings of the aetiology of mental disorders. Some psychiatrists were convinced that mental illnesses had biological causes, just like other illnesses. They developed and applied new physical therapies such as electroconvulsive therapy and leucotomy, which they hoped would target the physical origins of mental disorders while also aligning psychiatry to developments in general medicine (Shorter). Other psychiatrists were interested in their patients' psychological symptoms, and the ways in which patients' psychosocial environments influenced their mental wellbeing. These psychiatrists developed a model of social psychiatry and sought to establish therapeutic communities within their hospitals, building on wartime experiments in the use of group treatment methods for soldiers displaying psychological symptoms (Harrison and Clarke; Mills and Harrison; Whiteley). In so doing, they hoped to 
counter institutionalisation by transforming mental hospitals into actively therapeutic environments.

This article examines how psychiatrists who subscribed to different therapeutic approaches narrated their efforts to transform psychiatric practice within their memoirs. It focuses on accounts authored by William Sargant, an advocate of the physical therapies, and Denis Martin and David Clark, both associated with social psychiatry and the therapeutic community approach. Temporally-located views of the space and place of mental healthcare underpinned all three narratives, for the authors premised the need for reform on the legacy of therapeutic pessimism and authoritarianism, physically embodied within Britain's antiquated psychiatric hospitals. However, while Martin and Clark sought to transform the lives of chronic patients within the old psychiatric hospitals, Sargant attempted to relocate psychiatric care within general medicine, discarding chronic patients and psychiatric hospitals as unsalvageable relics from the past. Undeniably, the authors' divergent views on the nature and treatment of mental illness partially account for differences in the ways they represent change. Yet this article argues that we also need to examine how psychiatrists represented their own role in enacting change within their narratives, for this helps account for the varying ways in which each writer represented psychiatry, mental hospitals, mental illness, patients, and the roles played by other parties in reforming mental healthcare.

\section{Biography}

An examination of the background and career of each author provides an insight into each doctor's views of mental illness, while also providing clues as to the personality of each writer, which would in turn shape their narratives. Of the three, William Sargant arguably achieved the most prominence within the profession. Born in 1907, Sargant studied medicine at Cambridge University and obtained his MB degree in 1933. Aged twenty five, he was appointed medical superintendent of St Mary's Hospital where he undertook research into the 
treatment of anaemia. This research, observed Ann Dally, was "largely spurious," and was eventually discredited. In 1934, Sargant fell ill; in his autobiography he explained that "a very severe but as yet undiagnosed lung infection so depressed me that I began to lose all interest in my medical research work .... I resigned my post and after three months decided to find easier work elsewhere" (1). His book subsequently recounted his experiences as a locum at Hanwell Hospital. Dally, however, recalled that Sargant "became depressed to the point of being mentally ill, spent time as a patient in a mental hospital, and became unacceptable as a future teaching-hospital physician." Despite the absence of supporting evidence, there is good reason to give credence to Dally's assertion, for she had trained under Sargant and knew him personally. Moreover, before her death Dally had been the custodian of Sargant's personal papers, and had been working on a biography of Sargant. Indeed Dally's revelation may well account for Sargant's representation of mental illness, and his vision of reform. While publically wishing to conceal his experience of mental distress, he may nevertheless have empathised with fellow sufferers, thus accounting for his desire to reform mental healthcare. By arguing that mental illness had physical causes which were amenable to biomedical interventions, Sargant sought to recast his own breakdown in a manner which he found acceptable: a consequence of physical ill-health. His tendency to distinguish between acute mental illness, which he viewed as treatable via biomedical interventions, and chronic mental illness, which he depicted as having a very poor prognosis, could be interpreted as evidence of Sargant's ambivalence regarding his identity, and his relationship with other people who also suffered from mental illness (Goffman).

Following a spell in general practice in Nottingham, Sargant joined the staff at the Maudsley Hospital, which was then led by Professor Edward Mapother. Mapother sought to raise the status of academic psychiatry by creating a centre for clinical excellence at the Maudsley, favouring the value of empirical research (Jones). Here, Sargant experimented 
with physical therapies such as insulin coma therapy and cardiazol. During the course of the Second World War, Sargant applied physical therapies such as sedation, abreaction, ECT and leucotomies to servicemen being treated at the Sutton Emergency Hospital (Dally). Ambivalent towards Aubrey Lewis, who succeeded Mapother in 1946, Sargant looked for other positions. In 1948, he was appointed consultant psychiatrist to St. Thomas's Hospital in London-a post he held until his retirement.

Sargant served as registrar for the Royal Medico-Psychological Association between 1952 and 1971, and as President of the Section of Psychiatry for the Royal Society of Medicine in 1956-57. He was appointed as the main consultant for "The Hurt Mind," the BBC's first television series on mental illness, broadcast in 1956 (Long, 194-213). In 1944, Sargant published his textbook, An Introduction to Physical Methods of Treatment in Psychiatry, which he co-authored with Eliot Slater: the book subsequently went to five editions. Sargant also published two popular accounts of brainwashing: Battle for the Mind (1957) and The Mind Possessed (1973). Sargant firmly believed that psychiatry was simply a facet of general medicine, and predicted that mental illness would cease to exist by 1990 (Dally). His slavish devotion to physical therapies, his advocacy of leucotomies, and his willingness to experiment has polarised opinion on his work and legacy; his work at St Thomas's has proved to be particularly controversial (Maw; Li Shen Ooi). He was, observed Ann Dally, "one of the best loved and most hated" of twentieth-century psychiatrists.

Born in 1920, David Hazell Clark received his medical degree from Edinburgh University in 1943. During the Second World War, he worked as an army medical officer and was involved in the liberation of the concentration camps. Clark explained in an oral history interview that this experience gave him "a horror both of people being locked up, but also what being gaolers did to the people who did it," and that as a psychiatrist he subsequently found "the degradation and the oppression, but also the brutality of the worst back wards 
deeply disturbing" (Adams, 90). Following the War, he returned to Edinburgh University to train as a psychiatrist, and then moved in 1950 to the Maudsley Hospital in London, under the directorship of Aubrey Lewis. Here, he developed an interest in social psychiatry, and worked alongside S. H. Foulkes, who had pioneered group therapy with soldiers during the War (Kennard, Burns).

Recognising that there was little prospect of a permanent position at the Maudsley, Clark applied for the post of Physician Superintendent at Fulbourn Hospital in Cambridge in 1953. Aged only thirty three, he believed that he had little prospect of securing the job, but realised part way through the interview that he might be offered the post and panicked, because the hospital "was appalling! Well, not appalling, but - a seedy, shabby, demoralised, run-down place, and I thought, 'Do I want to commit myself to that?'” (Adams, 93). Despite his initial repulsion towards the Hospital, Clark became the youngest physician superintendent in England, and remained at Fulbourn for the next thirty years, retiring in 1983 (Burns). His memoir correspondingly presents an entwined narrative of his career and Fulbourn Hospital. During his career at Fulbourn, Clark spent a year at the Institute for Advanced Studies at Stanford University; served as a consultant for the World Health Organisation on mental health services in Japan, Peru, Argentina and Poland; and co-founded the Association of Therapeutic Communities (Burns). Aside from The Story of a Mental Hospital, which will be discussed in this article, Clark published Administrative Therapy in 1964, Social Therapy in Psychiatry in 1974, and Descent into Conflict: A Doctor's War in 1995.

No obituary can be located for Denis Vincent Martin, the author of Adventure in Psychiatry, although obituaries exist for his predecessor John Stuart Harris-who like Sargant trained at the Maudsley Hospital under Mapother-and for the psychiatrists Elizabeth Shoenberg and John Pippard, appointed to Claybury by Harris in 1958 and 1955 respectively. 
Perhaps this reflects Martin's ability to undertake his work in an inconspicuous manner, a trait which certainly manifests in his memoir. Martin qualified as a doctor in 1940 (The Lancet, 1940), and was awarded his diploma in psychological medicine by the University of London in 1949 (The Lancet, 1949). He was appointed to Claybury by Harris in 1954, where he served as deputy before succeeding Harris as Physician Superintendent in 1961, upon Harris' retirement (British Medical Journal, 1987). A year after his appointment to Claybury, Martin published an influential article in The Lancet in which he outlined how the regime of the mental hospital institutionalised patients by removing their responsibilities and fostering dependency (1955). He published a number of articles on psychotherapy, the therapeutic community, and nurses' roles. Martin also had an interest in the relationship between religion, medicine and healing, publishing on this topic and serving on a working party set up by the Archbishop of Canterbury in 1962 to examine whether greater cooperation could be achieved between doctors and clergy (The Lancet 1963, 845). He was forced to retire on health grounds in 1969 (Schoenberg, 8). One obituary for John Harris noted that Martin had predeceased Harris, who died in 1986 (DP).

\section{Representing the Past}

Sargant, Martin and Clark situated the reform of mental healthcare within a temporal landscape, largely adhering to a chronological narrative in which earlier forms of mental healthcare, embodied by the traditional mental hospital, were displaced, either by the agency of the author or as part of broader processes of change. Let us turn first to William Sargant, who went to work at Hanwell Mental Hospital in 1934. If Ann Dally's biographical account of Sargant is accurate, Sargant would have taken up his post at Hanwell not long after he himself had received treatment as a patient in a mental hospital. Constructed in the nineteenth century to provide for pauper lunatics, Sargant depicted 1930s Hanwell as a traditional 
authoritarian mental hospital, characterised by brutality and hopelessness. He inferred that little had changed since the building opened and suggested that it was impossible to surmount the legacy of the Victorian era. Sargant accordingly described the "hundred-year-old Hanwell Lunatic Asylum" as "a gloomy building surrounded by a massive brick wall," "a typical Victorian locked-up mental hospital" (1-2), "a dead end, full of terrible suffering for which I could do nothing" (13). Here, according to Sargant, nurses sought to lighten their load by heavily dosing difficult patients with bromides or paraldehyde. Lacking any effective means of treating mental disorder and theoretically responsible for around 500 patients each, the doctors attended to minor physical ailments and recertified patients between leisurely meals and games of tennis, in which junior doctors were expected to cede victory to senior colleagues. "I suppose we had advanced somewhat since the eighteenth century when the habit of whipping prisoners, sometimes to drive the devil out of them, still continued," Sargant grudgingly conceded (4).

This description is what we might expect from Sargant, who believed that mental illnesses had physiological causes and wanted to integrate mental healthcare within mainstream medical practice. His objective was thus to portray mental hospitals as archaic institutions beyond reform and out of synch with medical developments. Sargant explained in his preface that "the main purpose of this autobiography is to describe the fascinating progress that has taken place during the last thirty years in the discovery of medical and surgical approaches to the treatment of the mind of man" (vii). It is striking that Sargant's first chapter is on Hanwell, for this breaks with the chronological frame that structures the rest of the book; the following chapter pitches readers back to Sargant's childhood. The message we take from this is that Sargant's experiences at Hanwell cannot be slotted into his 
narrative of medical progress; mental hospitals existed in a nineteenth-century time warp seemingly disconnected from other developments in medicine.

It is, however, surprising that Martin and Clark offer very similar depictions of the mental hospitals they inherited. Of the two, Martin presented the more congenial picture. $\mathrm{He}$ depicted Claybury Hospital in the 1950s as a late nineteenth-century traditional authoritarian mental hospital, albeit a benign and well-run one. Progressive improvements had commenced, however the scope of action had been constrained by inadequate resources. Mirroring Sargant, Martin explained how in the traditional mental hospital the average doctor, responsible for around 300 patients, chose to make their rounds of the chronic wards quickly so as to free up time for those patients who appeared to benefit most from assistance. The quiescent chronic patient who caused no trouble helped facilitate this goal, enhancing the appeal of a disciplinary system in which patients submitted to the authority of nurses. Moreover, medical personnel had to contend with antiquated buildings which embodied the ideals of Victorian psychiatry and were extended on an ad hoc basis to accommodate growing numbers of patients. Within this large institution, Martin wrote, "the individual is frequently lost sight of as a unique person to be cared for in a personal way" (24). Martin's account was doubtless tempered by the fact that he was not Superintendent during the period described in the book. The Superintendent, Dr J. S. Harris, had been in post since 1938 and stepped down when the book was published. Harris, indeed, authored the introduction to the book. Predictably, perhaps, Martin's book stressed continuities with a long-established, well-run, benevolent regime; his message is that the system can be reformed.

In his account, Clark described "the asylum world of the 1940s," when mental hospitals were "the centre of English psychiatry." Although the brutality and suffering which permeated Sargant's narrative were absent from Clark's depiction of the traditional mental 
hospital, Clark nevertheless represented mental hospitals as institutions frozen in time which concealed abandoned patients. Psychiatry as a profession, he inferred, had likewise come to a standstill:

These large ancient institutions - most of them built in the 1850s - stood outside cities .... A broad drive would sweep through woodland, past cricket grounds and shrubberies up to an imposing entrance. Inside were shining floors and spotless corridors ... . [I]t was only as you penetrated further, into the back corridors, the airing courts and the wards that the vast mass of human hopelessness became apparent .... [Y]ou would be shown into big bare rooms, crowded with people, with scrubbed floors, bare wooden tables, benches screwed to the floor. There was a smell in the air of urine, sweat, paraldehyde, floor polish, boiled cabbage and carbolic soap ... . [T]here might be pleasant admission wards with flowers and pictures, kindly nurses and cooperative patients. But behind these were always the "back wards" filled with people for whom hope had been abandoned - the "chronics," the "back ward patients," the incurables and the intractable. (33-35)

By the close of the Second World War, he claimed:

Doctors had not discovered much since 1800 ... . For most psychiatric disorders ... little had been discovered in way of treatment, let alone cure. Patients were brought to the asylum, often furiously disordered; they quietened down and often stayed there for the rest of their lives. The disorders were given labels - mania, melancholia, stupor, delirium, paranoia, dementia praecox, schizophrenia. However, these labels made 
very little difference to how those suffering from such disorders were handled, nor to how their damaged lives developed and ended. (25)

New physical treatments, Clark noted, were applied in admissions wards after the War, but "prior to my arrival the basic premise of Fulbourn had been the traditional humane custodialism of British asylum management: look after patients kindly until they die, or perhaps, by chance, recover" (85).

While Martin's account appears to have been written with his predecessor breathing down his neck and was duly respectful, Clark was evidently not so encumbered, peppering his memoir with impertinent anecdotes and observations about the hospital's former superintendents. One, he recalled, was "chiefly remembered as a keen gardener and tennis player" (16), while another was "a little red-faced bachelor [who] was famous for his shooting parties" (26). Clark described his immediate predecessor as weighing "a gargantum 22 stone" who "expressed concern about new developments and distaste for all the postwar bustle and innovation" (38).

\section{Enacting Change}

All three accounts commenced by portraying antiquated and authoritarian hospitals to demonstrate the need for change, and then from this platform narrated how reform was accomplished. Sargant presented himself as a risk-taker who bravely battled the oppressive medical establishment - military metaphors abound in the text - in a heroic bid to alleviate the sufferings of his patients. In such an adventure, casualties were unavoidable. "Some doctors prefer to take few such risks at all," he acknowledged, "but this means patients can remain hopelessly incarcerated for life in a mental hospital with sufferings that are too terrible to 
contemplate" (159). Sargant described himself as a "games scholar," offered a place at medical school not because he excelled at medicine, but because he played football and rugby. In the Dean's view (and by inference, Sargant's too,) “a bright academic boy might end up in a mental hospital suffering from schizophrenia, whereas the rugger man, unless a plain fool, would somehow fight his way over the medical touchline" (21). In light of Dally's revelation, this anecdote points to Sargant's efforts to painstakingly reconstruct his identity by distancing himself from his experience of mental illness. Indeed, Sargant's discussion of his student days was more weighted to discussion of rugby and hedonism than of medical training. "The modern medical student ... would be shocked at our wholehearted abandonment to wine, women and song," he confessed. "A main function of the now extinct breed of hospital porters was coping with these drunken young gentlemen, later to become silk-hatted professional physicians ... . [W] hen we were off, we were off in every sense" (26). Sargant recalled attending a party at which he had consumed a mix of gin and champagne, before returning to the hospital at dawn and undertaking a surgical procedure. "I had learned my lesson," he recalled. "Never on any account to get so drunk as to risk a patient's life" (28). This anecdote, doubtless incorporated to amuse his readership, encapsulates how Sargant's reckless experimentalism tended to override concerns for patient safety.

Given that Martin's memoir was entitled Adventure in Psychiatry, one might anticipate a similarly racy narrative centred on the author's escapades. Yet the title is something of a misnomer. Throughout the book, Martin substituted Sargant's "I" with "We": this emphasised the collective nature of the enterprise while obscuring any errors made by Martin, any opposition to the changes introduced, and indeed individual responses to the changes. "The work described is not that of one man, nor of a small group, but of the whole community, both staff and patients" (viii), insisted Martin. Throughout, use of the passive 
tense concealed agency, presenting the processes of change as a natural consequence of enlightened thinking. Indeed, Martin's narrative depicted Claybury Hospital, its staff and its patients as an organic entity. Again, one explanation for this collective tone could be Martin's unwillingness or inability to take credit for the changes given Harris's role as Superintendent during the period described. However, Martin's refusal to depict himself as an agent of change may also have reflected his desire to serve others and avoid conflict, and his unwillingness to step into the limelight. Only in the preface did Martin adopt a first-person narrative, and here he took the opportunity to write himself out of the narrative as an agent of change, insisting that "the changes described arose out of the working life of the hospital and in so far as this book is a faithful record of them I have done no more than serve as a scribe for the whole community which is Claybury" (IX). The book, dedicated to the patients and staff of Claybury Hospital, excluded the personal reminiscences found in the other two memoirs.

Clark's account, by contrast, started off in a very personal, rather Sargant-esque tone, in which Clark narrated how he introduced changes, led the Hospital and battled against apathy, inadequate resources, institutionalised staff and patients and a parsimonious hospital committee. Part way through, however, Clark acknowledged that he was not winning this battle, observing "I often felt utterly daunted by the task of altering and moving things and feared that I might be utterly defeated by the apathy of the place and fail to achieve anything" (57). Rethinking his position, Clark decided that "I should not any more assume that all advancement at Fulbourn was to my credit, nor that all misfortunes were my fault" (140), and reconceptualised his role as that of a facilitator (149). Thus, a narrative which had commenced as the story of a heroic outsider overthrowing antiquated practices transformed into an entwined history of Clark, Fulbourn Hospital, and the therapeutic community. Indeed, 
for Clark the Hospital and the therapeutic community became coterminous, presenting difficulties for the author as the two pulled apart again at the end of his account.

\section{The Treatment of Long-Stay Patients}

Sargant consciously titled himself in his book as a physician rather than a psychiatrist, to emphasise his view that mental illness was the same as any other illness and should be treated according to the same principles that governed medical interventions in general hospitals. Ostensibly, Sargant supported mental hospitals, writing that "the treatment given there may be very good" (146). However, one barely has to read between the lines to arrive at a different conclusion. Sargant, for example, contrasted his strategy with the "unfortunate misconception" that "encouraging the admission of less seriously ill patients somehow increases the morale of chronic cases." When this is attempted, Sargant argued, "all that happens is that the newcomer's morale may rapidly descend nearer to the level of the chronic cases, simply because he now ranks as a similar mental hospital patient." It was far preferable, Sargant insisted, to provide in-patient care in a general hospital, so as to avoid "mental-hospital stigma" (148). What can one infer from this? Essentially that there is nothing to be done for the chronic patient and that it is pointless to attempt to reform mental hospitals. Following the inauguration of the National Health Service, Sargant described how he seized the opportunity to integrate the treatment of mental illness into general medical practice, a development facilitated by the new physical therapies. "Mental illness and its treatment," he claimed 'had become at last a true part of general medical treatment" (147). Promptly setting up an out-patient unit, through which drugs, electric shock and modified insulin treatments were administered, and a ward for in-patients, Sargant insisted that patients were treated the same as those on any ordinary medical or surgical ward. With the introduction of the tranquilizer chlorpromazine, Sargant explained how "even the acutest 
schizophrenic" could be kept tranquilized "while electric shock treatment and other methods speeded their recovery" (148).

The therapeutic measures advocated by Sargant have been credited with transforming psychiatric practice and facilitating the discharge of hitherto long-stay patients. Yet his autobiography focused almost exclusively on the applicability of these treatments to acute cases and how they might enable such patients to be treated outside the mental hospital. A rare example to the contrary surfaced when Sargant recollected a trip to Alabama where he visited an institution for black veterans. On his visit to the back wards, where he found “negroes strapped down in chairs, like poor King George III," Sargant alighted upon a plan: why not give some of these "pitifully agitated patients ... the benefit of modified leucotomy operations," a measure, Sargant noted, which was "simpler and cheaper" than that which preceded it. Sargant believed that his "negro-rescue plan" also offered "a wonderful chance ... [to] do a controlled experiment" by comparing the results of fifty operative cases with fifty control cases, and persuaded Walter Freeman to offer his services as surgeon for free. Justifying his suggestion, Sargant argued that “the negro's suffering could certainly not be any worse after the operation" (130), a rationale that failed to convince the Veterans' Hospital Association, which forbade the experiment. In some respects, the tale typifies the rhetorical devices present throughout Sargant's memoir; Sargant conjured an archaic vision of the brutal asylum where suffering patients were restrained like George III to justify an invasive procedure. Yet the combination of the patients' ethnicity and chronicity amplified Sargant's latent experimental streak, producing a situation in which more interest appears to be staked in the experiment than the well-being of the patients. By and large, Sargant believed that if mental illness had been left to run unchecked then the disease process would, in time, scar the patient. Physical therapies, he suggested, could have little impact when 
utilised at this late stage. In the "bad old days" before the introduction of physical treatments, he explained, repeated attacks of illness left patients "scarred" and eventually in a chronic condition (154).

Denis Martin believed that chronic patients had been created by the old system which institutionalised them if they failed to respond to orthodox treatments, and agreed with Sargant that long-stay patients benefited little from physical therapies. In his view, however, such patients could benefit from the therapeutic community approach, and he turned his attention to transforming the hospital environment by opening up communication, erasing hierarchies and dispensing with obsolete rules so as to unpick the authoritarian regime which institutionalised long-stay patients. Sargant viewed cure as the benchmark of success, and believing chronic patients to be incurable, abandoned this patient group. Martin pursued other objectives, reporting that even those who did not recover sufficiently to leave hospital now enjoyed friendlier relationships with staff and benefitted from greater freedom. For such patients, Martin believed, the ability to live in the hospital "with the freedom and dignity of individual people, rather than as 'chronic deteriorated patients'," was crucial. He objected to the way in which the term "back wards" still connoted an "implication of therapeutic neglect and hopelessness" (133). However, Martin's assertion that patients were individuals was rather undercut by his tendency throughout to use the grouped description of "patients."

Early in his memoir, Clark echoed Sargant's rather dehumanising portrayal of chronic patients. Clark emphasised the amorphous and homogenous nature of Fulbourn's long-stay patients: "grey faced, clad in shapeless, ill-fitting clothes," they "stood still or moved about aimlessly;" they "made little impression on me ... shapeless ... crumpled ... shuffling ... unkempt ... sagging ... coarse" (1). He described the patient "scrubbing gang" who cleaned the corridors as "grey-haired, grey-overalled gnomes" (53). Yet Clark acknowledged that 
while patients' shabby appearance was typically attributed to disorder and self-neglect, it was often due to a lack of individual clothing and the reliance on cheap, hard wearing fabric which could be boiled in the patient laundry.

Clark observed that while "some doctors still thought that the 'old asylum chronics' were best left in peace" (33), "my view was that chronic patients could be actively helped towards recovery and that furthermore the way to do this was to change the way they lived within the asylum" (85). He focussed first on ensuring that all patients were employed in some way and then sought to foster greater self-government amongst the patients. Sargant had described how he had left Hanwell in despair and found consolation in the treatment of acute cases of mental disorder. Clark, by contrast, reflected "I had enjoyed my time at the Maudsley, but felt guilty whenever I went out to a mental hospital and saw the neglected hundreds. I thought that rather than spending my time on a few people with minor difficulties I should be working for the much greater number of suffering and abandoned people incarcerated in long-stay mental wards" (40). In this objective, Clark was inspired by a WHO pamphlet on “The Community Mental Hospital” which stressed that patients' individuality should be preserved and suggested that patients had a greater capacity for responsibility and independence than recognised.

These were sentiments which Martin shared, although Martin rarely described patients individually in his memoir. Clark, however, provided sketches of some of the Hospital's patients who he inferred had been failed and, to some degree, exploited by the previous regime. One patient named Caroline, Clark noted, was "often offered to newly arrived doctors' wives as a useful servant and nanny," and although classified as feebleminded, "her intelligence was not far below normal" (53). Similarly Charles, aged 63 and admitted to the hospital in 1906 as a disturbed mental defective, had "for many years 
been the personal servant of the former superintendent" (54). Clark often returned to these individuals later in his memoir to demonstrate how the regime he had enacted had improved their lives. Caroline, for example, benefitted from the liberalisation of the Hospital's regime and began going on shopping trips and Women's Institute outings. Helped with her clothes and hair by a fellow patient, Clark commented that they "looked just like any two middleaged country women in town." Caroline's story was brought to closure once she had been settled as a resident domestic in an old people's home (121). Two features in this story resonated more broadly within Clark's account - the capacity of patients to help one another, and his tendency to characterise women's improvement in particular in terms of their appearance. Elizabeth, for example, "asked to have her hair washed and set. Her hair was permed and she kept it neat. Her dresses were well looked after. She started using some lipstick and enjoyed the weekly dances" (120).

\section{Conclusion}

What role does the past serve in these stories of reform? For Sargant, the only way to reform mental healthcare was to irrevocably break with the past. In his autobiography, Sargant used the spectre of the gothic Victorian asylum and the deteriorated chronic psychotic to justify his espousal of invasive and often dangerous medical interventions. He positioned himself as an outsider to psychiatry who sought to integrate the treatment of acute cases of mental disorder within general medicine, relegating mental hospitals and chronic patients. Consequently, most of his narrative related to work outside the mental hospital. In his efforts to reform care and treatment for acute cases of mental disorder, he reinforced the stigma attached to chronic mental disorder and the mental hospital. Mental illnesses, Sargant believed, were caused by physiological factors, and interpersonal relationships were 
insignificant. This latter point is reflected in Sargant's decision to depict himself as an autonomous agent of change.

Martin and Clark echoed Sargant's depiction of antiquated authoritarian mental hospitals in which doctors and nurses, lacking effective therapeutic interventions, sought to control deteriorated and dehumanised chronic patients. However, their narratives remained largely within the walls of the mental hospital as they described how they sought to transform mental hospitals into therapeutic environments which could address the emotional problems experienced by long-stay patients and rekindle their independence. By erasing all evidence of his own role in enacting change, Martin's narrative emphasised the role of interpersonal relationships in improving mental health; his depiction of a relatively smooth transition may well have reflected his own desire to avoid conflict. Conversely, Clark's memoir initially reads as the narrative of a heroic outsider battling obstacles. He detailed, for example, the poorly trained nurses who denigrated patients and the hostility of the junior doctors, who "spent long sessions discussing my faults and the inadequacies of the hospital" and "criticised my dependence on the nurses, my anxiety, my garrulity, my authoritarianism" (140). Rehabilitation, Clark recognised, was a slow, difficult and frequently painful process. He discussed the difficulties of establishing ward meetings on the disturbed women's ward where one patient throttled staff and patients alike and the opposition of the hospital's management committee who took "the news of a number of deaths of patients ... with equanimity" yet "were deeply concerned" "when it was announced that swine fever had broken out in the [hospital's] pig herd" (72). This was not the account of the omnipotent doctor enacting change; rather, Clark's memoir unambiguously depicted the constraints within which he acted. Given the limited financial resources available within the system, the desire to individualise the chronic long-stay patient expressed by Martin and Clark was 
paradoxically undercut by their recognition that the only way of helping so many was to deliver mass services - mass occupational therapy (or as Clark termed it, work for all, which he acknowledged could be dreary, degrading and worthless) (121) and mass psychotherapy, delivered by junior doctors, nurses, orderlies and other patients. Martin in particular spent so much time in group meetings on wards and with different staff groups that he no longer had time to spend with patients on an individual basis. The lack of resources available to mental healthcare providers would continue to overshadow efforts to rehabilitate long-stay patients.

The legacy of these three psychiatrists is rather mixed. When Cambridge established its first chair in psychiatry, it had been assumed that Clark would be appointed to the post. However, the role was offered instead to Martin Roth, who had trained alongside Sargant under Mapother at the Maudsley and favoured biological approaches to psychiatry. Inevitably, Roth and Clark clashed. Roth, Clark recalled, "found much that he disliked about psychiatry in Cambridge - and he made his distaste apparent. He found the culture of open discussion which we had developed at Fulbourn quite unacceptable ... . He could see no value in the therapeutic community approach" (232). Clark described how the Cambridge psychiatrists divided into rival camps which competed over resources: in this struggle, academic psychiatry gained the ascendency over social psychiatry. Perturbed by the demise of the egalitarian culture at the doctors' meetings, Clark withdrew to his work in the Rehabilitation Service, taking like-minded nurses, social workers and occupational therapists with him (232).

Clark had invested his career in transforming Fulbourn Hospital by embedding within it the principles of the therapeutic community. Unsurprisingly, he struggled to reconcile himself with the dissolution of the bonds between the Hospital and the therapeutic community after his departure, which threatened to render his legacy ephemeral. On the one 
hand, he observed that "we had indeed released the people from the back wards, and in the process abolished the back wards themselves" (233). Moreover, the care of people who suffered from enduring mental health problems had been transformed, and most now lived "good lives" in the community (242). Yet Clark regretted the demise of the therapeutic community, which he believed to be incompatible with "the authoritarian, bureaucratic organisation which the NHS has gradually become" (235), and viewed the resurgence of locked wards with some alarm. Indeed, in 1994 Clark's achievement of transforming Fulbourn into an open doors hospital was dismantled when the Department of Health constructed a new locked unit at Fulbourn, "ringed with flood-lit high fences and firmly locked" (245). Healthcare policy may have progressed with the elimination of long-stay wards, but Clark believed that healthcare ideology had regressed, fuelling a repressive culture which threatened to undermine patients' dignity and independence. "The conditions that created the need for Social Therapy in asylums," Clark concluded, "are being set up again in gaols, secure institutions and locked wards" (243).

The social psychiatrist Tom Burns echoed Clark's evaluation: Roth, he claimed, eroded Clark's initiatives at Fulbourn. Yet we need to remind ourselves that what counted as progress in psychiatry - or, for that matter, regression - was a subjective and time-bound matter. In his interviews with former Fulbourn staff members, John Adams found that even some of Clark's supporters welcomed Roth's appointment. Fulbourn, they feared, had failed to keep pace with developments in biological psychiatry, while the democratic principles of the therapeutic community had fuelled anarchy and compromised safety. Roth, these interviewees believed, had the capacity to once more transform Fulbourn into a progressive hospital (275-77). 
Roth's appointment reflected the fact that the social psychiatry approach espoused by Clark and Martin is now a weaker force within contemporary psychiatric practice, while the biological psychiatric model championed by Sargant is currently in the ascendency. Sargant's view of mental disorders as illnesses best treated by biomedical interventions in community settings has triumphed - for now. Yet Sargant's reputation has become increasingly tarnished over time, as former patients and colleagues have publicised details of the experimental treatments undertaken by Sargant at St Thomas's with seemingly little or no oversight (Maw; Davies). Sargant's gung ho attitude towards radical interventions, and his tendency to ride roughshod over issues of consent and oversight, clashes with contemporary sensibilities within psychiatry.

Collectively, these narratives illuminate divergences in psychiatrists' views of the nature and treatment of mental illness in post-war psychiatric practice. Yet these first-hand memoirs offer, at best, only a partial and distorted window into the states of mind of each author in relation to changing psychiatric practices and the patients in their care. Clark's memoir entwines the author's life and experiences with the history of Fulbourn Hospital in which he worked for thirty years, while his fellow nurses, doctors and patients assume the role of a supporting cast, whose views are rarely presented. In Martin's memoir, Claybury Hospital comes to the fore as an organic and cohesive entity in the process of reform and renewal which subsumes the identities and views of its residents, including Martin himself. Sargant's narrative is the only one of the three to transcend the space of the mental hospital, following the author's international adventures over the course of his career. Yet paradoxically Sargant's self-representation served to distance him from his own experiences of mental distress, and from the sufferers of long-standing mental illness whom he depicts as pitiable but silenced figures. 


\section{Works Cited}

Adams, John. “"Challenge and Change in a Cinderella Service': A History of Fulbourn Hospital, Cambridgeshire, 1953-1995.” PhD Diss. Open University, 2009.

Anonymous. "Royal College of Physicians of London." The Lancet, Nov. 9 1940, 610.

Anonymous. "University of London.” The Lancet, May 14 1949, 848.

Anonymous. "Notes and News: Clergy and Doctors.” The Lancet, Oct. 19 1963, 845.

Burns, Tom. "Clark, David Hazell (1920-2010), Psychiatrist.” Oxford Dictionary of National Biography. Oxford: Oxford University Press, 2014.

[http://www.oxforddnb.com/view/article/102600, accessed 23 July 2014].

Clark, David H. The Story of a Mental Hospital. Fulbourn 1858-1983. London: Process Press, 1996.

Dally, Ann. "Sargant, William Walters (1907-1988), Psychiatrist." Oxford Dictionary of National Biography. Oxford: Oxford University Press, 2004.

[http://www.oxforddnb.com/view/article/40195, accessed 23 July 2014].

DP. “John Stuart Harris.” Bulletin of the Royal College of Psychiatrists, vol. 11, April 1987, 146.

Davies, Barbara. “The Zombie Ward: The Chilling Story of how 'Depressed' women were put to Sleep for Months in a Room at an NHS Hospital.” Daily Mail, August 8 2013, 58. 
Goffman, Erving. Stigma. Notes on the Management of a Spoiled Identity. Harmondsworth: Penguin Books, 1968.

Harrison, Tom and Clarke, David. "The Northfield Experiment." British Journal of Psychiatry160 (1992): 698-708.

Jones, Edgar. "Aubrey Lewis, Edward Mapother and the Maudsley.” Medical History 22 (2003): 3-38.

JSP. “J S Harris.” British Medical Journal, 294, Jan. 3 1987, 63.

Kennard, David. “Obituary. David Clark: Pioneering Psychiatrist who Breathed New Life into Mental Health Care." The Guardian, May 12 2010, 35.

Li Shen Ooi, Joanne. "How Loud is the Unquiet Mind? William Sargant (1907-88) and British Psychiatry in the Mid-20 ${ }^{\text {th }}$ Century.” Journal of Medical Biography 20 (2012): $71-78$.

Martin, Denis V. “Institutionalisation.” The Lancet, vol. 266 issue 6901, Dec. 3 1955, 118890.

Martin, Denis V. Adventure in Psychiatry. Social Change in a Mental Hospital. Oxford: Bruno Cassirer, 1962.

Maw, James. "Revealing the Mind Bender General." BBC documentary, broadcast on Radio 4, March 172009.

Mills, John A. and Harrison, Tom. "John Rickman, Wilfred Ruprecht Bion, and the Origins of the Therapeutic Community." History of Psychology 10 (2007): 22-43. 
Sargant, William. The Unquiet Mind: The Autobiography of a Physician in Psychological Medicine. London: Heinemann, 1967.

Shoenberg, Elizabeth (ed.). A Hospital Looks at Itself. Essays from Claybury. London: Faber and Faber, 1972.

Shorter, Edward. A History of Psychiatry. From the Era of the Asylum to the Age of Prozac. New York and Chichester: John Wiley \& Sons, Inc., 1997.

Whiteley, Stuart. "The Evolution of the Therapeutic Community." Psychiatric Quarterly 75 (2004): 233-48. 